
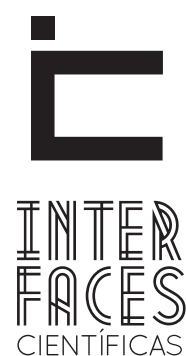

HUMANAS E SOCIAIS

\title{
TESOURO DE MENINAS E TESOURO DE MENINOS: LEITURA DE CIVILIDADE NA AMÉRICA PORTUGUESA
}

Fabiana Sena da Silva ${ }^{1}$

\section{RESUMO}

Este trabalho analisa os livros Tesouro de meninas e Tesouro de meninos na América Portuguesa. Tesouro de meninas é versão portuguesa do original, de autoria de Pauline de Montmorin, conhecida como Madame Leprince Beaumont, que escreveu e publicou esta obra de caráter pedagógico em 1757. Esta foi traduzida pelo padre português Joaquim Ignácio de Frias em 1774. O Tesouro de meninos, por sua vez, foi escrito pelo francês Pierre Blanchard e traduzido pelo português Matheus José da Costa. Embora não haja o registro da sua primeira edição, supõe-se que seja do século XVIII. Essas narrativas ficcionais chegaram ao Brasil graças às listas de pedidos de envio de livros ao Rio de Janeiro dirigidas a Real Mesa Censória, em Portugal. Os títulos de Tesouro de meninas e Tesouro de meninos fornecem indícios de um gênero até agora pouco estudado: livros de civilidade. Tais obras introduziram os leitores brasileiros aos códigos de sociabilidade, conforme foram se expandindo as redes de sociabilidade no período joanino.

\section{PALAVRAS-CHAVE}

Livros de Leitura. Civilidade. Leitores. 


\section{ABSTRACT}

This work analyzes the books "Tesouro de meninas e Tesouro de meninos na América Portuguesa” (Girls Treasure and Boys Treasure in Portuguese America). "Tesouro de Meninas" is the original portuguese version, written by Pauline de Montmorin, known as Madame Leprince Beaumont, who wrote and published this work of pedagogical character in 1757.Treasure Girls This was translated by the Portuguese priest Joaquim Ignacio de Frias in 1774. The "Tesouro de Meninos", in turn, was written by French Pierre Blanchard and translated by the Portuguese Matheus José da Costa. Although there is no record of the first edition, it

\section{RESUMEN}

El presente trabajo hace un análisis de los libros Tesoro de Niños y Tesoro de Niñas en la América Portuguesa. Tesoro de niñas es la versión original en portugués, autoría Pauline de Montmorin, conocida como Madame Leprince Beaumont, quien escribió y publicó esta obra de carácter pedagógico en 1757. Esto fue traducido por el sacerdote Portugués Joaquim Ignácio de Frias en 1774. El tesoro de los chicos, a su vez, fue escrito por el francés Pierre Blanchard y traducido por el hombre portugués José da Costa. Aunque no hay registros de su primera edición, se supone que será el siglo XVIII. Estas narrativas ficcionales han llega- is supposedly from the 18th century. These fictions narratives arrived in Brazil through lists of requests for sending booksto Rio de Janeiro directed to Portugal's Royal Censorship. The titles of "Tesouro de Meninas" and "Tesouro de meninos" provide evidence of a genus so far little studied: civility books. Such works introduced Brazilian readers to sociability codes, as networks expanded in the Joanine Period.

\section{KEYWORDS}

Reading Books. Civility. Readers.

do a Brasil gracias a listas para enviar libros a Rio de Janeiro destinadas a medidas de censura Real en Portugal tabla. Valores de Tesoro de Niñas y tesoro de niños, proporcionan la evidencia de un género poco estudiado hasta ahora: libros de civismo. Dichas obras han introducido a los lectores brasileños a códigos de sociabilidad, como fueron ampliando la $\mathrm{n}$ de redes de sociabilidad en el período jónico.

\section{PALABRAS CLAVE}

Leyendo libros. Civismo. Lectores 


\section{INTRODUÇ̃̃̃O}

Os estudos sobre a leitura, o livro e o leitor na contemporaneidade aproximaram os pesquisadores na recuperação da história da leitura no Brasil. Esse interesse, no entanto, somente ocorreu no final do século XX, quando se tornou possível identificar livros e outros impressos que circularam no País nos Setecentos e nos Oitocentos. No movimento da restituição das práticas de leitura dessa época, os livros e a leitura ganham centralidade, ocupando um lugar de destaque entre os pesquisadores de letras e da história da educação interessados em saber como eram encaminhadas as situações de leituras no cotidiano escolar e em outros espaços no passado. Dessa forma, emergiram inúmeros títulos, possibilitando responder algumas das questões apontadas por Darnton (1992) a respeito da recuperação da história da leitura: "quem, o que, onde, quando, como e por quê".

$\mathrm{Na}$ perspectiva de conhecer especificamente o que os leitores do início dos Oitocentos liam, este estudo focaliza os livros de civilidade, gênero dos mais frequentes na América Portuguesa a partir do final do século XVIII, cujo objetivo era introduzir regras de comportamentos sociais nas pessoas. Os livros, vindos de Portugal, serviam de referência aos leitores interessados em transitar em uma sociedade que se moldava por meio das normas de conduta.

Dessa forma, modificando o cenário cultural e educacional, as regras de civilidade tomaram relevância com a chegada da Corte Portuguesa na América em 1808, quando os novos espaços criados em virtude da presença da Corte exigiram novos hábitos e costumes entre a população que já residia aqui, europeizando a vida social deles - "o refinamento das maneiras e sofisticação do gosto” (RAINHO, 1995, p. 139). Essa transformação possibilitava "ao mesmo tempo nivelar-se (pelo menos na aparência) aos seus pares europeus e distinguir-se do resto da população" (RAINHO, 1995, p. 139). Para tal empreendimento, os livros tornaram-se instrumentos para a divulgação da civilidade, ensinan- do a nova nobreza e as classes em ascensão a se comportarem socialmente, a exemplo de 0 amigo da juventude; Tesouro da paciência; $O$ amigo das mulheres; Avisos de uma mãe a seu filho; Instruções de uma mãe a sua filha; Instrução da mocidade e Livro dos meninos, Recreação de um homem sensivel; Tesouro de adultas; Tesouro de adultos; Aviso de uma mãe a sua filha; Cartas de uma mãe a seu filho; Instruções de um pai a seu filho; Instruções de uma mãe a seu filho; Lições de um pai a sua filha; Tesouro de meninas; Tesouro de meninos (AUGUSTI, 1998).

Entre os livros do gênero da civilidade, Tesouro de Meninas (1757), de Madame Leprince de Beaumont ${ }^{2}$ e Tesouro de Meninos $(\mathrm{s} / \mathrm{d})^{3}$, de Pierre Blanchard ${ }^{4}$,marcaram presença significativa entre os leitores do Rio de Janeiro nos primeiros anos do século XIX. Essas obras chegaram às mãos dos leitores cariocas por meio de so-

2. Jeanne Marie Leprince de Beaumont nasceu em Rouen, França, em 1711. Em 1748, surgiu seu primeiro trabalho: Le Triomphe de lavérité ou mémoires de M. de La Vilette. Partiu para Londres aproximadamente em 1750 para lá viver e se ocupou da educação de nobres jovens. Essa atividade inspirou Beaumont para trabalhar nos periódicos ingleses, colocando-se a escrever, sob o título de Magasins, tratados de educação para usar com as crianças, os adolescentes e as damas. Entre 1750 e 1780, foram 40 volumes produzidos por ela, entre os volumes mais conhecidos estavam Magasindes enfants ou Dialogues entre une sagegouvernante et sesélèves(Londres, 1757, 4 vol. in-12), Magasindesadolescents, ou Dialogues entre une sagegouvernante et sesélèves(Londres, 1764, 4 vol. in-12). Antes de morrer, em 1780, ela deixou escrito tratados de moral ehistória, gramática e teologia (BUISSON, 1911).

3. Embora não haja o registro da sua primeira edição, supõe-se que seja do século XVIII. Um dado, em seu interior, trata da sua possível data de publicação, quando o personagem, pai de família, relata um fato que ocorreu em 1787. Assim, suponho que este livro tenha sido escrito e publicado após esta data.

4. 0 autor não deixou traços da sua existência. Apenas se sabe que, posteriormente a obra que ora analiso, ele publicou outra de título similar, diferenciando o subtítulo que fornece o assunto da obra: Tesouro de meninos: resumo de história natural para uso da mocidade de ambos os sexos, e instrução das pessoas que desejam ter noções da história dos três reinos da natureza. Compilado e ordenado por Pedro Blanchard, e traduzido em português com muitas correções e artigos novos por Matheus José da Costa. Lisboa, na Imp. Regia $8 .^{\circ} 6$ tomos com estampas. 0 tomo $1 .^{\circ}$ publicado em 1814 , contém a Cosmografia e Mineralogia. - 0 tomo 2. ${ }^{\circ}, 1815$, a Botânica. O 3. ${ }^{\circ}, 1817$, Zoologia, mamíferos. - 0 4. ${ }^{\circ}$, ibi, Continuação dos mamíferos, aves. - 0 5. ${ }^{\circ}$, 1819, Continuação das aves, peixes. - 0 6. ${ }^{\circ}, 1830$, Continuação dos peixes, crustáceos, testásseis, répteis, vermes, insetos, polipos, zoófilos, etc. - A nomenclatura portuguesa adotada nesta obra foi disposta pelo insigne Brotero (SILVA, 1858-1923). 
licitações de livros, dirigidas a Real Mesa Censória em Portugal, cujo papel era "secularizar o controle e as proibições religiosas, que havia longo tempo restringiam a entrada de idéias no país" (SCHWARCZ, 2002, p. 108). $\mathrm{Na}$ relação da lista de pedidos de livros pela Real Mesa Censória, apresentada por Abreu em Caminhos do romance (2003), Tesouro de meninas e Tesouro de meninos ocuparam o quarto e o oitavo lugar, respectivamente, em 1808, entre os leitores cariocas. Esses livros sobre conduta social adquiriram tanta importânciano período joanino, que, durante o Império, estiveram presentes em diversas escolas de Primeiras Letras: nas províncias da Paraíba, do Rio Grande do Sul, do Amazonas e da Bahia, conforme os relatórios dos presidentes dessas províncias. A circulação desses dois livros de leitura demonstra que a temática da civilidade permaneceu no horizonte da formação do Estado brasileiro durante o Império.

Com efeito, Tesouro de meninas e Tesouro de meninos tratam de civilidade por disseminarem regras de condutas aos leitores da época. Mas, de acordo com essas obras, o que podemos entender sobre civilidade? Como se configuram as normas contidas nelas para as pessoas se tornarem civilizadas? Qual a importância da civilidade na América Portuguesa? Na busca de responder às questões, a análise das duas obras se centrou nos seus conteúdos, apresentando como ocorria o processo de civilizar o outro.

A civilidade está relacionada diretamente às regras do comportamento social, mas também se refereàs noções éticas, morais, designações sociais e esferas do público e do privado. Ao longo da história, todas as sociedades elaboraram preceitos para normatizar as relações entre as pessoas para que vivessem em harmonia. A partir do século XV e XVI, na Europa, a divulgação das regras de civilidade, por meio dos livros do gênero da civilidade, a exemplo de Civilidade Pueril (1530), de Erasmo de Roterdam, instituiu um novo modo de viver no mundo, pois, até então, tudo era compartilhado e todos viviam em um mesmo espaço: a divisão da casa, separando o ambiente íntimo do social - quarto e sala, comer com seus próprios talheres e copos, usar guardanapo, falar em tom moderado, escolher as temáticas de conversação, a depender do ambiente em que estavam e das pessoas a sua volta, vestir roupas apropriadas para determinados tipos de eventos, ter gestos contidos etc. (ELIAS, 1994).

De acordo com Chartier (2004, p. 45), durante os século XVI e XVIII, as regras da civilidade "visaram submeter as espontaneidades e as desordens, assegurar uma tradução adequada e legível da hierarquia dos estados, desenraizar as violências que dilaceravam o espaço social".

Schwarcz (1997), por meio do seu ponto de vista antropológico, afirma que a voga da civilidade partiu da Corte francesa no século XVIII, servindo de modelo para outras classes e países no século XIX. Conforme Schwarcz (1997, p. 11), “o comportamento nobre e cortês passa a ser comparado aos modos do camponês, rude, e a postura oposta a deste é recomendada e ensinada a adultos e crianças". Assim, a civilidade é compreendida como modo de agir e de conviver na sociedade, sendo sinônimo de boas maneiras, de polidez, de refinamento dos costumes (STAROBINSKI, 2001).

A difusão das luzes, no Iluminismo, fez com que as regras da civilidade fossem divulgadas, também, para as pessoas que não pertencessem à aristocracia. Os livros de diversos gêneros literários, incluídos os de civilidade, começaram a chegar à classe média e à camponesa alfabetizada em versões populares, já que os originaisnão eram vendidos a preços módicos.

Disseminar as normas de conduta é o que objetivavam os manuais de civilidade na América Portuguesa, servindo como os principais instrumentos de leitura entre os que almejavam transitar nos novos espaços sociais que foram criados após 1808. Nessa perspectiva, "os manuais de ci- 
vilidade cumpriam o papel de ensinar um conjunto de regras necessárias para o bom desempenho da vida social, baseadas, fundamentalmente, na aparência e nas formas de apresentação de si aos olhos dos seus iguais" (PECHEMAN, 2002, p. 82).

Passando à análise dos livros, constatamos que, em Tesouro de meninas e Tesouro de meninos, a ficção é o gênero utilizado pelos autores para ensinar aos leitores a serem civilizados, apresentando limites entre o real e o irreal, cujo padrão é determinado pela temática da civilidade - o real - discutida pelos personagens - figuras irreais, mas que aproximavam o conteúdo do leitor, em especial, o infantil. Em Tesouro de meninas, os personagens são a aia Bonna e as suas discípulas, formadas por sete meninas - Sensata, Babiola, Espirituosa, Molly, Mary, Carlota e Altiva - na faixa etária dos cinco aos 13 anos. Já em Tesouro de meninos, os personagens se apresentam como o Pai de Família e seus dois filhos - Paulino, 12 anos, e Felícia, 11. Nas obras, os personagens Bonna e o Pai de Família civilizam as crianças por meio do diálogo, assumindo a função de mestres.

Os títulos das obras chamam a atenção, a primeira vista, por delimitar os destinatários, configurando leituras para meninas e para meninos. $\mathrm{Na}$ verdade, esses livros foram destinados ao público em geral, conforme assegura o tradutor de Tesouro de meninas, Joaquim Ignácio de Frias (1846), ao mencionar que essa obra é endereçada a pais e mestres, dando-lhes o verdadeiro segredo da educação, bem como ao verdadeiro patriota interessado na educação da sua mocidade.

Em Tesouro de meninos, também podemos perceber o mesmo público-leitor da obra quando a Borel Borel Cia, importante editora, formada por livreiros franceses que se instalaram em Lisboa em torno de 1762 (NEVES, 2005), afirma que "tivemos em vista uma obra útil para a educação da Mocidade tanto Portuguesa como Brasileira" (BO-
REL BOREL CIA., 1851, p. 1. Grifo nosso). Nessa afirmação, percebe-se que os destinatários podem ser os mesmos apontados pelo tradutor de Tesouro de meninas - pais, mestres e alunos - já que essa obra se refere a educação da mocidade.

No que se refere ao diálogo, forma como está estruturada a ficção dessas obras, os autores recuperaram um modelo antigo desse gênero para divulgar o conteúdo da civilidade, cuja forma é notabilizada por Sócrates, Platão e Aristóteles para ensinar. 0 uso do diálogo pelos autores compatibiliza com a noção que Comenius apresentou em sua obra Didática Magna, de 1631, a qual contém cinco razões para que o livro seja composto em forma de diálogo. Entre essas razões, duas delas, expressas pelo fundador da didática moderna, mostram a importância do diálogo para o aprendizado:

2. Os diálogos excitam, animam e reavivam a atenção, precisamente pela variedade das perguntas e das respostas, e pelos diferentes motivos e formas destas, sobretudo se nelas se misturam coisas agradáveis; mais ainda, pela variedade e troca dos interlocutores, não só o espírito se liberta do tédio, como, estendendo mais o campo da sua atividade, se torna sempre mais desejoso de estar a ouvir. 3. 0 diálogo torna a instrução mais sólida. Com efeito, da mesma maneira que recordamos melhor um fato que nós próprios vimos, que um fato que apenas ouvimos referir, assim também na mente dos alunos permanecem mais tenazmente fixas as coisas que aprendem por meio de uma comédia ou de uma conversação (pois, nestes casos, thes parece não só ouvir, mas também ver o fato) que as que apenas ouvem contar de uma forma nua pelo professor, como o demonstra a experiência. (COMENIUS, 1996, p. 120).

Também podemos perceber que o uso do diálogo para civilizar as crianças está na perspectiva horaciana miscuitutiledulci para ensinar aos leitores as regras e os modelos de sociabilidade. Ao passo que o diálogo contribui para tornar o processo de civilização mais próximo dos leitores, ele possibilita aplicar a estratégia para instruir para a civilidade. Dito de outro modo, a conversação revela os artifícios dos "tutores" para modelar e polir o comportamento dos outros personagens. 
Nesse sentido, a conversação entre os personagens se configura como um jogo exemplar. A conduta apropriada para as crianças é apresentada por Bonna e o Pai de Família, os quais as estimulam à aprendizagem da civilidade por meio de histórias, contos, fábulas, associando-as às próprias ações do cotidiano. No caso de Tesouro de meninas, o jogo fica mais evidente pelo fato de as personagens terem seu papel demarcado pelo significado dos seus nomes, cujas falas expressam claramente a sua função no diálogo: Babiolla, Espirituosa e Altiva são as personagens-antítese, e Carlota, Molly e Mary são as meninas comportadas, mas que, em algum momento, demonstravam atitudes más e traziam seus exemplos para o diálogo a fim de refletirem e se "emendarem" (BEAUMONT, 1846). Dessa forma, os seus nomes, carregados de sentidos, bem como o diálogo entre elas, podem ser comparados a um jogo em que Bonna objetiva civilizar as meninas, inculcando-lhes o modelo de conduta feminino da época: virtuosa, obediente e dócil, significando ser civilizadas.

Em Tesouro de meninos, o jogo se torna mais sutil em decorrência de os personagens infantis aderirem de imediato ao processo de civilização e por não apresentarem mal comportamento durante a narrativa, tornando as crianças, portanto, exemplares. Diferentemente da personagem Bonna, o Pai de Família não precisa tornar seus filhos bons, mas, sim, imprimir-lhes as regras de civilidade, virtude e moral para viverem bem na sociedade. As crianças eram exemplares e demonstravam amor entre si e o pai tratava-as sempre com bastante docilidade e vice-versa. O Pai de Família inicia a conversa alegando que os filhos necessitam conhecer como devem se conduzir as pessoas com honra em uma sociedade. 0 diálogo entre os três personagens é estabelecido a partir da demonstração de interesse dos seus filhos, em particular o de Paulino, quando este diz: "Muito bem sabeis quanto gostamos de nos instruir, principalmente querendo vós ser o mestre. Ensinai-nos, sim, ensi- nai-nos a ser bons, e amados de todos, assim como vós o sois; e este será o melhor patrimônio que receberemos da vossa mão" (BLANCHARD, 1851, p. 13. Grifo nosso). A partir de então, eles conversam sobre os modos de agir na sociedade, sendo virtuosos e tendo moral.

Na obra, a civilidade é definida da seguinte maneira:

O termo Civilidade é derivado de outro, que significa Cidade, assim, na primitiva acepção, Civilidade, quer dizer maneira de viver dos habitantes de uma cidade entre si. Com efeito, a Civilidade compreende todas as regras, segundo as quais nos devemos conduzir na Sociedade. (BLANCHARD, 1851, p. 158. Destaque do autor).

Esse conceito evidencia que a civilidade não está somente no campo da aparência, da apresentação exterior, mas, sim, da igualdade, sem a distinção de classe. Embora as sociedades fossem estruturadas por classes sociais, no século XVIII, período do Iluminismo na França, a distância entre a nobreza e a burguesia foi diminuída, já que as normas de conduta foram estendidas para esta última classe.

Ainda que existam muitas semelhanças entre Tesouro de meninas e Tesouro de meninos, a diferença entre as obras está nas estratégias para civilizar as crianças. Em Tesouro de meninas, a modificação dos hábitos das suas discípulas ocorre quando Bonna utiliza a repetição e a confissão para realizar a sua tarefa de tornar as meninas virtuosas, obedientes e dóceis. O testemunho da personagem Sensata, a discípula exemplar, revela o procedimento da repetição:

[...] eu só creio que, se sou comedida, o devo a minha aia. Ela me diz todos os dias que há duas sortes de esperteza: uma que só serve para nos fazermos aborrecer, e desprezar de todos; e outra, que nos faz amáveis, dóceis, virtuosas, e que obriqa a dizer, a quem nos conhece, bem de nós; e toda vez que ela me pressente alguma leviandade, logo me repreende. (BEAUMONT, 1846, p. 11. Grifos nossos). 
Quanto ao procedimento da confissão, este é demonstrado, em outra passagem, no diálogo entre Bonna e sua discípula Carlota:

\section{Bonna}

[...] mas dizei-me, Carlota, não vos ocorreu nada, ouvindo a história de Caim?

Carlota

Alguma coisa me lembrou, mas não atrevo a dizê-la por ser vergonhosa.

Bonna

Não vos acovardeis, menina; pois quem chega a confessar os seus defeitos. Não tem dúvida de corrigi-los. Carlota

Pois então eu a digo: Olhai, eu sou invejosa como Caim, a respeito de minha irmã mais velha: meus pais a amam mais do que a mim, e isto me faz desesperar, e certamente eu a mataria se pudesse.

Bonna

E não é por vossa culpa que vossos pais amam vossa irmã do que a vós? Dizei-me: Se vós fosse casada, e tivesse duas filhas, das quais uma fosse agradável, honesta, obediente, e doce a seus Mestres; e a outra teimosa, maligna, descortês para todos, e desobediente aos Mestres, qual amareis vós mais?

Carlota

A primeira.

Bonna

Logo não deveis ofender-vos de vossos pais quererem mais a vossa irmã do que a vós: fazei-vos vós tão boa como ela, e então vereis como eles vos estimam precisamente.

Carlota

Aceito o conselho, Senhora Bonna, e vos prometo escrever todas as loucuras que disser, e obrar.

Bonna

E eu vos prometo que se o fizerdes, seja infalível a emenda, e que vos fareis tão amável quanto a vossa irmã mais velha, e tão ditosa como ela, por estar certa que não viveis a vosso gosto por serdes má. (BEAUMONT, 1846, p. 61 e 62. Grifos nossos).

As perguntas de Bonna nos dois primeiros destaques do trecho acima revelam a estratégia de persuasão que ocorre por meio da comparação e da imitação, encontrada também em Quintiliano (1944), como meios de persuadir pela eloquência. Essa estratégia leva Carlota a se sentir culpada por não ser amada pelos seus pais, porque é má. As perguntas de Bonna, também, podem ser compreendidas na perspectiva da confissão, como uma estratégia de purificação. Por meio dessas estratégias a mestra a faz concluir o óbvio: "Logo não deveis ofender-vos de vossos pais" (BEAUMONT, 1846, p. 62), pois a culpa é de Carlota. A alternativa que a mestra dá a sua discípula é que ela deve seguir o comportamento da irmã para que tenha o amor dos pais. Tal procedimento não compromete a mestra, por soar como conselho, assim como Carlota o entende. No entanto, é a própria Carlota que se compromete ao dizer para Bonna que escreverá todas as loucuras que disser e obrar, atribuindo a si o castigo para se purificar. Essa aprendizagem evidencia a repetição oral e escrita, fixando o ensinamento da mestra, a qual arremata a sua estratégia, afirmando: "Se o fizerdes, seja infalível a emenda". Dessa forma, a seguinte passagem do diálogo ilustra bem essa estratégia da personagem Bonna:

\begin{tabular}{l} 
Mary \\
Pois tanto que alguém é mau, logo se torna um mons- \\
tro e lhe nascem pontas? \\
Bonna \\
Não, menina, o vosso corpo fica como é; mas a vossa \\
alma se fará feia, e mais abominável do que um mons- \\
tro se não fordes boa. \\
Carlota \\
Eu tenho bons desejos de ser boa, e se muitas vezes \\
eu sou má e cometo alguma loucura é sem o conside- \\
rar. Eu não quero que me desmintam; e quando se me \\
nega o que desejo, faço-me então má, castigo a minha \\
criada, injurio minhas irmãs e zombo de meus pais, e, \\
para evitar isto, peço que me digais o que devo fazer. \\
Bonna \\
Não, menina, vós não sois má contra vossa vonta- \\
de, podendo nós sempre ser boas, se procuramos os \\
meios, os quais vos mostrarei aqora. Primeiramente \\
deveis pedir a Deus todas as manhãs e noites, nas vos- \\
sas orações, graças para vos emendardes, porque nós \\
não podemos nada sem o seu socorro; mas é preciso \\
pedir-lhe esta graça com eficácia e como vós pedis \\
a vossa mãe o que mais desejais. Em segundo lugar \\
deveis reparar vossos erros, pedindo perdão a vossa \\
criada, rogando a vossas irmãs vos advertiram, e pedir- \\
-lhe vos relevem, quando as ofenderdes; e se quereis \\
emendar-vos seriamente, escrevi todas as noites as \\
más palavras, que tiverdes dito aquele dia, pois estou \\
certa que isto vos causará pejo para mais as não di- \\
zerdes.Representar-se-vos-á, que Deus vos vê cometer \\
\hline
\end{tabular}

Pois tanto que alguém é mau, logo se torna um monstro e lhe nascem pontas?

Bonna tro se não fordes boa.

Carlota rar. Eu não quero que me desmintam; e quando se me nega o que desejo, faço-me então má, castigo a minha criada, injurio minhas irmãs e zombo de meus pais, e, .

Não, menina, vós não sois má contra vossa vontade, podendo nós sempre ser boas, se procuramos os não podemos nada sem o seu socorro; mas é preciso pedir-lhe esta graça com eficácia e como vós pedis a vossa mãe o que mais desejais. Em sequndo lugar the vos relevem, quando as ofenderdes; e se quereis zerdes.Representar-se-vos-á, que Deus vos vê cometer 
todas essas loucuras, que vô-las repreende, e quese vos não emendardes, vos castigará ou nesta vida, ou depois da morte, o que vós não iqnorais.

Carlota

Já ouvi dizer isso, mas nunca the dei atenção.

Bonna

Não duvido, menina, sendo certo que só é má quem não considera no que vos digo; e para fazer lembrar-vos a todas destas coisas, devo instruir-vos na Escritura Santa. É este um livro Divino, que foi ditado pelo Espírito Santo, e por isso devemos lê-lo, aprendê-lo e repeti-lo com um profundo respeito. Vós conhecereis, lendo esta bela história, quanto o deveis amar, e quanto deveis recear de ofendê-lo, porque castiga os maus severamente. Lembrai-vos também, minhas filhas, que esta história é a única, de que nos não é ilícito duvidar do que é certo que é dia quando faz Sol. A Deus, senhoras, espero alegrar-me com a vossa aplicação. (BEAUMONT, 1846, p. 44 - 47. Grifos nossos).

Nesse trecho, está claro que Bonna utiliza a comparação para modelar o comportamento das meninas, seja comparando com os personagens das histórias, seja entre as suas próprias discípulas. Essa estratégia obriga as meninas a confessarem os seus erros, que estão relacionados à falta de respeito com as pessoas da sua família ou com as demais pessoas que as cercam, e se propõem a se modificar. A tarefa imposta por Bonna, para corrigir os erros das meninas, é a repetição por escrito das más ações provocadas por elas. Dessa forma, a importância do diálogo fica evidenciada, pois ele permite às crianças a falar sobre as suas condutas errôneas, refletir sobre as suas práticas e agir de acordo com a honestidade e a integridade, como ditam os bons costumes. De acordo com o prólogo do tradutor Joaquim Ignácio Frias, o diálogo é simples e singelo, no qual se revela uma estratégia discursiva para que a personagem Bonna obtenha as confissões de suas discípulas.

Quanto ao Tesouro de meninos, a análise se centrará na última temática da obra, a civilidade. Como foi apontado anteriormente, o Pai de Família não aplica estratégias para modificar o comportamento dos seus filhos. Ele apenas discorre sobre as regras apropriadas para seus filhos viverem em harmonia na sociedade, de modo que versa sobre todos os tópicos relativos às práticas cotidianas que exigem regras de civilidade, quais sejam: do levantar da cama, da maneira de vestir e do asseio; do respeito devido às pessoas idosas; da docilidade e da condescendência; do modo por que nos devemos conduzir na conversação; do modo por que nos devemos conduzir em uma companhia; de como nos devemos conduzir em uma companhia; de como vos deveis conduzir à mesa; de como nos devemos portar no jogo; de como nos devemos comportar pelas ruas; do que os homens devem por civilidade às senhoras; da maneira como as pessoas de pouca idade hão de se conduzir em sociedade a respeito das pessoas mais idosas; de como devemos nos portar, quando nos acharmos com pessoas de diversas religiões; do deitar na cama (BLANCHARD, 1851).

Por meio desses tópicos, a aprendizagem da civilidade está no controle do corpo - "disciplinar as almas por meio da coerção exercida sobre o corpo e impor à coletividade das crianças uma mesma norma de comportamento sociável” (REVEL, 1991, p. 176), bem como no controle do tempo para estabelecer regras que se iniciam na manhã e finalizam à noite: 'do levantar da cama' até 'do deitar na cama'.

Um dos tópicos apontados pelo personagem Pai de Família demonstra que ele não objetiva modificar o comportamento das crianças por meio de estratégias, como as de Bonna, mas apenas ditar as regras de civilidade. A seguinte passagem serve para ilustrar essa abordagem:

Se a escolha dos jogos vos é permitida, preferi sempre os que dão mais exercício ao corpo, como a péla, a bola, o volante, etc.; qualquer destes consegue melhor o seu fim, qual é o distrair o espírito, além de serem mais úteis à saúde. Os jogos de cartas, das damas, do xadrez, etc.; pelo contrário, pregando-vos sobre uma cadeira, esquentam o corpo, e pela atenção, que exigem fatigam o espírito. É isto um novo trabalho. Aceitai-vos, porém com bom ar, se outras pessoas os propuserem; pois que (ainda vo-lo torno a repetir) só devemos cuidar na sua utilidade, e no seu prazer; os homens se reúnem em sociedade para acharem satisfação uns pelo outros; é necessário, portanto, que todas as vontades se unam em uma só. (BLANCHARD, 1851, p. 211. Grifo nosso). 
Nesse trecho, o Pai de Família orienta os jogos que devem ser jogados em benefício do corpo, apontando para a noção de que se educa e se instrui uma criança para viver em sociedade, sendo o jogo um dos meios mais adequados para esse objetivo, já que a criança não se tornará civilizada em causa própria, mas, sim, em favor de uma convivência social. Assim, a sua vontade deve estar em harmonia com a das demais pessoas. Ao longo da narrativa, verifica-se que a sociedade é enfatizada pelo Pai de Família, o que evidencia que ele educa Paulino e Felícia para viverem nela.

A função desempenhada pelos personagens de Bonna e do Pai de Família de modificar o comportamento das crianças pode ser vista como polidora, já que visa "a transformação da grosseria, da rusticidade em civilidade, urbanidade, cultura", segundo Starobinski (2001, p. 26). Ainda na perspectiva do autor, o polimento se configura como um

[...] trabalho de escultor (na ordem do esmero das formas e dos volumes), de cuteleiro (na ordem do afiamento, da fineza e do corte), de espelheiro (na ordem da limpidez refletora). Polir, [...] é "tornar um corpo uniforme em sua superfície, tirar-lhe todas as irregularidades, tirar as pequenas partes que tornam áspera a superfície; tornar claro, luzente à força de esfregar [...]". Diz-se particularmente das coisas duras. (STAROBINSKI, 2001, p. 26. Grifo do autor).

A partir da análise dessas obras, é possível perceber que as prescrições ali presentes revelam as "máscaras" (STAROBINSKI, 2001) que a criança deve usar na sociedade, a exemplo de uma passagem de Tesouro de meninos: "Levai à Sociedade um ar doce, cortês, até mesmo alegre” (BLANCHARD, 1851, p. 201). Se, por um lado, o uso de máscaras se configura como a dissimulação para encobrir os verdadeiros sentimentos, por outro, faz-se necessário o seu uso, já que “a vida teria tornado intolerável, sobretudo nas condições de promiscuidade física da época, se o costume não impusesse à casa uma certa disciplina" (ARIĖS, 1978, p. 14).
Contudo, os livros ora analisados não divulgam um assunto inédito, já que, ao longo da história, todas as sociedades criaram regras de convivência, com o objetivo de promover uma harmonia nas relações entre os grupos e as pessoas. Assim, as regras encontradas em ambas as obras conduzem para as publicações renascentistas, delimitando o lugar de onde partiram a tradição da civilidade, divulgando as regras de convivência entre os nobres. Esse lugar está marcado em 0 cortesão (1528), de Castiglione Baldassare, e A civilidade pueril (1530), de Erasmo de Rotterdam, cujas obras foram de grande circulação na época.

A frequência da reimpressão e adaptação d'O cortesão e A civilidade pueril propagou o gênero educação de príncipes ou "espelho de príncipe" (HANSEN, 2002). Tal gênero literário veiculou condutas - cortesia e civilidade - para a Corte, instituindo um arquétipo que se fixou nos leitores dos séculos seguintes, sendo adaptado conforme a sociedade a que pertencia. Esses impressos propalaram regras de como agir com o próximo em casa e na rua, como conversar, o que conversar, como tratar as pessoas mais velhas, como se comportar em ambientes públicos, como agradar as pessoas, como ser virtuoso, como se preparar para as armas, como se vestir, como comer, como jogar, como dormir. Essas regras tinham um endereço certo: a aristocracia. Embora destinadas aos príncipes, educados para agirem corretamente na Corte, essas regras podiam interessar às pessoas relacionadas à Corte, as quais eram aspirantes a príncipe ou a cortesão, primeiros destinatários desse gênero.

No século XVIII, com o lluminismo na França, as regras de civilidade foram divulgadas a todas as pessoas, a exemplo de Tesouro de meninas e Tesouro de meninos, que, de forma didática, revelam as regras de condutas das pessoas em geral, extrapolando os limites aristocráticos, estendendo para a burguesia, classe em ascensão nesse período. Tal herança é advinda do código de boa conduta - cortesia e civilidade -, mostrando a permanência de uma tradição de longa duração da civilidade nos livros de leitura que circularam no Brasil desde o final do período colonial. 
De um modo geral, é possível afirmar que a civilidade em Tesouro de meninas e Tesouro de meninos visa ao controle dos sentimentos e dos maus comportamentos entre as crianças e outros leitores, como os jovens e os adultos, estabelecendo condições de um relacionamento lícito, disciplinante e homogeneizante para a vida em sociedade. Mas, no que tange à criança, ela é um ser que deverá ser regulado, moldado, polido para o convívio social, sendo afastado do vício e promovendo a virtude.

Com efeito, essas duas obras publicadas no século XVIII, que alcançaram grande sucesso junto ao público brasileiro no Império, permanecendo nas listas de livros à venda até o início do século $X X$, conforme Augusti (1998, p.20), tornaram-se referência e/ou inspiração para outros manuais de civilidade no período posterior no Brasil. Nessa perspectiva, tornar visíveis os conteúdos e as estratégias de aprendizagem dos livros que circularam pelas mãos dos leitores no Brasil colonial no cotidiano familiar, seja numa leitura silenciosa ou na voz de um narrador, e, anos depois, adentraram nas escolas de primeiras letras no Império, nos faz perceber onde repousam as regras de civilidade que ainda permanecem presentes nos dias de hoje, embora de outro modo, por meio da oralidade. Investigar, pois, o passado por meio desses manuais implica em reconhecê-los como uma "poderosa fonte de conhecimento da história de uma nação [...]" (LAJOLO e ZILBERMAN, 1998, p. 121), bem como na ordenação do mundo da leitura no Brasil.

\section{REFERÊNCIAS}

ABREU, Márcia. Caminhos do livro. Campinas: São Paulo: Mercado das Letras, 2003.

ARIĖS, Philippe. Prefácio. In: ERASMO. Civilidade Pueril. Lisboa: Estampa,1978.

AUGUSTI, Valéria. 0 romance como guia de conduta: A moreninha e Os dois amores. 1998. Dissertação
(Mestrado). Instituto de Estudos da Linguagem. Unicamp, São Paulo, 1998.

BEAUMONT, Madame Leprince. Tesouro de Meninas. Trad Joaquim Ignácio Frias. Lisboa: s.n., 1846. Disponível em: <http://www.caminhosdoromance.iel.unicamp.br/>. Acesso em: 19 jul. 2007.

BLANCHARD, Pedro. Tesouro de Meninos. Trad. Matheus José da Costa. 6.ed. Lisboa: s.n., 1851. Disponível em: <http://www.caminhosdoromance.iel.unicamp.br/>. Acesso em: 19 jul. 2007.

BOREL BOREL\& Cia. Dedicatória. In: BLANCHARD, Pedro. Tesouro de Meninos. Trad. Matheus José da Costa. 6.ed. Lisboa, 1851.

BUISSON, Ferdinand. Nouveau dictionaire de pédagogie et d' instructionprimaire. 1911. Disponível em <http://www.inrp.fr/edition-electronique/ lodel/dictionnaire-ferdinand-buisson/document. php?id=2974 >. Acesso em: 18 nov. 2007.

CHARTIER, Roger. A História Cultural: entre práticas e representações. Rio de Janeiro: Bertrand Brasil, 1986.

CHARTIER, Roger. A ordem dos livros: leitores, autores e bibliotecas na Europa entre os séculos XIV e XVIII. Trad. Mary Del Priore. 2.ed. Brasília: UnB, 1999.

CHARTIER, Roger. Distinção e divulgação: a civilidade e seus livros. In: CHARTIER, Roger. Leituras e leitores na França do Antigo Regime. Trad. Álvaro Lorencini. São Paulo: UNESP, 2004.

COMENIUS, João Amós. Didática Magna: tratado da arte universal de ensinar tudo a todos. Tradução e notas de Joaquim Ferreira Gomes. 4.ed. Lisboa: Fundação Calouste Gulbenkian, 1996.

DARNTON, Robert. História da leitura. In: BURKE, Peter (org.). A escrita da história: novas perspectivas. Trad. Magda Lopes. São Paulo: UNESP, 1992. 
ELIAS, Nobert. 0 Processo Civilizador: Uma história dos costumes. Rio de Janeiro: Jorge Zahar Editor, 1994, (v.1).

HANSEN, João Adolfo. Educando príncipes no espeIho. In: FREITAS, Marcos Cezar e KUHLMANN Jr. Moysés. Os intelectuais na história da infância. São Paulo: Cortez, 2002.

LAJOLO, Marisa e ZILBERMAN, Regina. A formação da leitura no Brasil. 2.ed. São Paulo: Ática, 1998.

NEVES, Lúcia Maria Bastos P. Luzes nas Bibliotecas de Francisco Agostinho Gomes e Daniel Pedro Muller, Dois Intelectuais Luso-Brasileiros. In: Actas do Congresso Internacional, Espaço Atlântico de Antigo Regime: poderes e sociedades.FCSH/UNL. Lisboa 2 a 5 de novembro de 2005.

PECHMAN, Robert Moses. Cidades estreitamente vigiadas: o detetive e o urbanista. Rio de Janeiro: Casa da Palavra, 2002.

QUINTILIANO. Instituições Oratórias. Trad. Jerônimo Soares Barbosa. São Paulo: Cultura, 1944, (v.2).
RAINHO, Maria do Carmo Teixeira. A distinção e suas normas: leituras e leitores dos manuais de etiqueta e civilidade - Rio de Janeiro, século XIX. ACERVO: revista do Arquivo Nacional.Rio de Janeiro, Arquivo Nacional, v.8, n.1-2, jan/dez., 1995.

REVEL, Jacques. Os usos da civilidade. In: ARIÈS, Philippe e CHARTIER, Roger (org). Da renascença ao século das luzes. Trad. Hildegard Feist. São Paulo: Companhia das Letras, 1991.

SCHWARCZ, Lilia Moritz (org). Introdução. In: ROQUETTE, J. I. Código o Bom-Tom, ou, Regras da Civilidade e de Bem Viver no Século XIX. São Paulo: Companhia das Letras, 1997.

SCHWARCZ, Lilia Moritz. A longa viagem da biblioteca dos reis. São Paulo: Companhia das Letras, 2002.

SILVA, Inocencio Francisco da. Dicionário bibliográfico português. Estudos de Innocencio Francisco da Silva aplicaveis a Portugal e ao Brasil. Continuados e ampliados por P. V. Brito Aranha. Revistos por Gomes de Brito e Álvaro Neves, Lisboa: Imprensa Nacional, v.23, 1858-1923.

STAROBINSKI, Jean. As máscaras da civilização: ensaios. São Paulo: Companhia das Letras, 2001.

\footnotetext{
1. Especialista em Metodologia da Pesquisa Científica pela Universidade do Estado do Pará. Universidade Federal da Paraíba. fabianasena@ yahoo.com.br 
